\title{
An introduction to inferentialism in mathematics education
}

\author{
Jan Derry ${ }^{1}$
}

Received: 9 July 2016 /Revised: 21 December 2016 / Accepted: 29 December 2016

C The Author(s) 2017. This article is published with open access at Springerlink.com

\begin{abstract}
This paper introduces the philosophical work of Robert Brandom, termed inferentialism, which underpins this collection and argues that it offers rich theoretical resources for reconsidering many of the challenges and issues that have arisen in mathematics education. Key to inferentialism is the privileging of the inferential over the representational in an account of meaning; and of direct concern here is the theoretical relevance of this to the process by which learners gain knowledge. Inferentialism requires that the correct application of a concept is to be understood in terms of inferential articulation, simply put, understanding it as having meaning only as part of a set of related concepts. The paper explains how Brandom's account of the meaning is inextricably tied to freedom and it is our responsiveness to reasons involving norms which makes humans a distinctive life form. In an educational context norms, function to delimit the domain in which knowledge is acquired and it is here that the neglect of our responsiveness to reasons is significant, not only for Brandom but also for Vygotsky, with implications for how knowledge is understood in mathematics classrooms. The paper explains the technical terms in Brandom's account of meaning, such as deontic scorekeeping, illustrating these through examples to show how the inferential articulation of a concept, and thus its correct application, is made visible. Inferentialism fosters the possibility of overcoming some of the thorny old problems that have seen those on the side of facts and disciplines opposed to those whose primary concern is the meaning making of learners.
\end{abstract}

Keywords Inferentialism E Epistemology·Pedagogy· Vygotsky· Brandom · Philosophy of mind

It is rare that a theory arrives on the scene sufficiently powerful to stimulate inquiry in a wide range of areas. Inferentialism though is such a theory. For the purposes of this

Jan Derry

j.derry@ucl.ac.uk

1 UCL Institute of Education, University College London, Bedford Way, London WC1H 0AL, UK 
special issue, it is interesting to note that it was developed by a philosopher, Robert Brandom, who majored in mathematics for his first degree and who was excited by the idea that mathematical languages could be extended to understand meanings in natural languages, including literary uses. Our interest here is of course mathematics education but the ideas treated below apply equally well to all areas of education. This paper is intended to serve as an introduction to the theory of inferentialism itself. Brandom's work on inferentialism is now being applied across a broad range of disciplines including law, political theory, history as well as education studies (Bakker \& Derry, 2011; Canale \& Tuzet, 2007; Erman, 2010; Klatt, 2008; Marshall, 2013). The task of providing concrete examples and working through the implications of the theoretical approach is relatively recent.

Locating inferentialism among the various theories relevant to mathematics education is not at all straightforward. Simply put it is a theory of meaning but this fails to do full justice to its theoretical reach. It is a theory which forms part of a move in thought which sees mind as inseparable from world and language "not as a formal structure but as a feature of the natural history of beings like us" (Williams \& Brandom, 2013, p. 372). Our understanding of the human mind was transformed over half a century ago when the cognitive revolution in psychology responded to the "science of behaviour" that had come to define psychology (Miller, 2003). The revolution in psychology acted as a counter attempt to bridge the gap between brain and mind by the development of a new interdisciplinary field; it was in a large part driven by interest in developments in artificial intelligence. By contrast, inferentialism attends to what is distinctively human. As it is has been developed by Brandom, inferentialism is a systematic theory which offers the possibility of thinking through old problems in refreshingly new ways. In keeping with other recent developments in philosophy, it places emphasis on activity and the development of meaning. With Vygotsky, it shares a Hegelian inheritance and as such it is concerned with the movement of thought rather than with snapshots that fail to do justice to the nature of thought. The idea of the movement of thought in the articulation of meaning is central to inferentialism since it shows that the meaning of a concept, rather than being fixed, is fleshed out by the inferential connections that constitute it. As these connections change, so the meanings of concepts alter. Although this may seem to be restricted to historical or philosophical concerns about how knowledge itself develops through inferential articulation (Rouse, 2011), these ideas can be extended to the pedagogical and educational domain (cf. Bransen, 2002). Most importantly, here for mathematics educators, inferentialism offers a powerful analytical tool to examine human activity through a more fine-grained account than is generally available within social scientific research. Indeed, Stekeler-Weithofer sees Brandom's major work Making it Explicit as developing a new perspective that sets a standard for "a whole field of knowledge, thinking, and research" (Stekeler-Weithofer, 2008, p. 1).

Despite the theoretical weight of inferentialism, the intention here is not to apply theory to practice where theory is assumed to provide direct prescriptions, as criticised by Cobb (2007). While there is no simple mapping of theory onto practice, innovations in theory can shed a new light on old problems and it is here that the tradition that informs the development of Brandom's inferentialism, as it is worked through, has much to offer. Theories serve here as a resource for opening up what is currently invisible. The inferentialist ideas developed below are drawn not only from Brandom but also from McDowell as 
well as Vygotsky, all of whom credit the influence of Hegel on their work (Derry, 2013).

When applied to education, inferentialism provides a way of thinking about teacher development, pedagogy and knowledge which sheds powerful insights into issues that are central to educational concerns (Bransen, 2002). Moreover, it fosters the possibility of overcoming some of the thorny old problems of education that have seen those on the side of facts and disciplines opposed to those whose primary concern is the meaning-making of individual learners. Seymour Papert characterised such opposition when he drew a picture of Instructionism at odds with his development of Constructionism. For Papert, Instructionism, often thought of simply in terms of the delivery of knowledge content, had a tendency "to overvalue abstract reasoning", understood as isolating "pure essential factors from the details of concrete reality" and then attempting to pass these on (Papert, 1993, p. 149). By contrast Constructionism, with its sensitivity to pedagogic issues, unleashed important qualities of being, of affectivity and the desire to create.

However, the move in recent years to attend to pedagogic issues has led to a neglect of knowledge and it is here that inferentialism offers insights. At the very least, it offers a way of reconfiguring how we think about these issues, it also opens the way to a more fine-grained account of pedagogic practice and of subject knowledge. Philosophy is about what it means to be human and inferentialism introduces this way of thinking into education. This may appear an esoteric point but it is our way of "being in the world" that distinguishes us from other life forms and, significantly for our purposes here, it is this way of being that allows a different orientation to the world to that of other life forms. Attention to what distinguishes humans underlies the account of inferentialism here. The human capacity for conscious self-determination, the nature of sociality, capacity for reason and the extent to which humans can transform environments - all play a decisive role in the following account. While other life forms are confined to an ecological niche, humans produce their environment and as part of this process "we humans are...symbol-mongers: we have the peculiar ability to let one thing stand for another" (Peregrin, 2014, p. 1). In popular educational rhetoric, these differences are too often ignored and claims such as chimpanzees or even birds are smarter than humans are made without regard to the particular character of human thinking. In an article entitled Are Birds Smarter Than Mathematicians? Herbranson and Schroeder (2010) run the observed behaviour of pigeons together with the concept of estimation stating, "Pigeons often perform quite impressively on tasks that require estimation of relative probabilities. In some cases, pigeons may even eclipse the performances of human participants" (Herbranson \& Schroeder, 2010, p. 2). Similarly, a BBC report speaks of the mental skills of humans and chimpanzees in the same vein and asks "Are you smarter than a chimpanzee...new research conducted by Japanese researchers suggests maybe not when it comes to memory and mental skills" (Chimps Are Smarter Than Us, BBC, 2007). These claims obscure the distinctive features of human thought. Our peculiar ability to let one thing stand for another, "and what the relationship so established consists in", as Peregrin notes, "is very difficult to explain in a nonmysterious way" (Peregrin, 2014, p. 1). Inferentialism, however, brings to light just those aspects of this process of representation which are significant for educationalists concerned with how learners grasp concepts; moreover, it confronts the question of precisely what this grasping of concepts comprises. 
In order to attempt to show the significance of Brandom's theory of inferentialism for education research, and in particular for mathematics education, this paper will start with the broader philosophical background which sees an aspect of human freedom as characterised by our responsiveness to reasons. This is crucial to any consideration of what is involved in learning. The next section will consider some of the implications of this distinctive feature of humans, indicating the importance of privileging the inferential over the representational when we consider how learners acquire meaning and knowledge. This is followed by a brief introduction to Brandom's conception of concept use as involving commitments to particular connections (relations) to other concepts and with this, his idea of deontic scorekeeping - the keeping track of our own commitments and those of others. The penultimate section shows a similar weight placed on the systematic relations of concepts by Vygotsky for whom the interconnection between concepts are necessary for deduction. The final section returns to the power of LOGO as characterised by the way in which the norms governing geometry are necessarily engaged with by learners using the software. The section ends with the crucial role of teacher judgement in fostering the conditions for effective learning.

\section{The broader philosophical context}

It is helpful to consider the broader philosophical context in order to grasp the extent to which these ideas are significant for educationalists (Bakhurst, 2011). Alongside Brandom, the work of his colleague John McDowell is particularly relevant here: together, Brandom and McDowell are known as the Pittsburgh Hegelians. They stand as two of the most significant contemporary philosophers renowned for moving beyond the tired divide between the analytic and continental traditions. This paper will mainly be concerned with Brandom's inferentialism but it is worth mentioning McDowell's ideas because in many ways, despite their differences, they complement it (Macbeth, 2009; Testa, 2009) and taken together, they provide a breadth of original thinking to enable a richer account of educational practice at the heart of which is epistemology.

In Mind and World, McDowell describes:

an inchoately felt threat that a way of thinking we find ourselves falling into leaves minds simply out of touch with the rest of reality, not just questionably capable of getting to know about it. A problem about crediting ourselves with knowledge is just one shape...in which that anxiety can make itself felt (McDowell, 1996, pp. xiii-xiv).

McDowell's target is the anxieties that have troubled philosophers since Descartes about how we can be in touch with the world at all. This is a long standing issue in philosophy and it is connected to the preoccupation of mathematicians with the relation of mathematics to the natural world (Wigner, 1960). The problem of how mind is in touch with the world has preoccupied philosophy but also underlies competing theoretical approaches in mathematics education. The anxieties that McDowell responds to arise from an oscillation between two alternative positions - between a "coherentism that renounces external constraints on thinking" and "a vain appeal to the Given, in the sense of bare presences that are supposed to be the ultimate grounds of empirical 
judgements" (McDowell, 1996, p. 24). In exposing what is presupposed in both positions, McDowell shifts attention from what we share with animals to what is distinctive about human beings, namely, our responsiveness to reasons. McDowell calls this responsiveness "a good gloss on one notion of freedom" (McDowell, 1996, p. xxiii). The appeal to a Given is the appeal to a notion of experience devoid of mind (that is independent of thought). Like Brandom, McDowell draws on the work of Wilfrid Sellars and what Sellars termed the Myth of the Given. The idea of the Given is that we have immediate awareness of the world from the very start, without concepts being in play, and that knowledge results from impressions that, having impinged on our senses, are interpreted by human construction. According to this view of things, concepts come into play late in the day after the world has already been taken in. This common and unexamined assumption of a bare Given upon which we make constructions pervades much pedagogic practice, Sellars' more technical critique involves an attack not just on the idea of impressions as data, but on "the entire framework of givenness" or what Hegel called immediacy (Sellars, 1997, p. 14) — that is, on the idea that our relation to the world is one of direct unmediated awareness. McDowell shows just how problematic the common assumption of a bare Given is when he asks "[h]ow can experience, standing in judgement over, say, a belief, return a verdict sufficiently favourable for the belief to count as knowledge?" if experience is made up of impressions it cannot serve as a tribunal (McDowell, 1996, p. xiii). In his resolution of this contradiction, McDowell insists that we need not identify nature solely with the law governed realm that we associate with science. We are in error if we exclude mind from nature. The distinctive characteristics of the life forms that are human are no less a part of nature than other organic entities. Yet to include the mind in nature does not entail a reductive naturalism. The apparent dichotomy, all too often assumed, between the natural and the normative or between nature and reason allows us to think of the content of experience as something separate from reason. However, for McDowell, "[e]xperiences have their content by virtue of the fact that conceptual capacities are operative in them" (McDowell, 1996, p. 66).

McDowell is concerned with the grip that modern naturalism has on our thinking and resists the idea that the sui generis character of the human species has either to be reduced to modern naturalism or to stand outside nature altogether as it does in the more familiar Cartesian dualism. Naturalism, the orthodoxy in contemporary Anglophone philosophy, assumes that all matters can be understood through methods used by the sciences. McDowell recognises the achievement of modern science in disenchanting nature and replacing superstition and belief with law-like accounts. However, he resists the idea that the application of scientific methods alone can provide a viable understanding of mind yet at the same time, he rejects the idea that what is distinctively human lies outside of nature. Instead, he insists that human second nature (the nature that arises as a result of human activity) is still part of nature but requires a different understanding from that of law-like accounts that are used for understanding matter. By shifting the focus to second nature in this way, McDowell gives priority to the development of our cognitive capacities by initiation into language and tradition. Initiation involves far more here than simply the acquisition of the means for communication, since through initiation into a language, children are brought into "a store of historically accumulated wisdom about what is a reason for what", and they thereby acquire "the capacity to think and act" (McDowell, 1996, p. 126). 
The shift of focus to seeing mind as part of nature, namely, second nature, makes possible a number of insights into how we think about cognitive capacities. These capacities are developed through the induction of the child into culture and tradition through specific activities and practices. The child becomes responsive not simply to causes that appear "given" by first nature but to reasons that are established in second nature. When a young child first learns a word, that word arises in a particular context and form of activity, not in a vacuum. It is already situated in a rich set of practices which gave it meaning. To put it another way, when young children utter the word "milk" when demanding a bottle, they have already begun to form a concept of milk arising out of their contact with it within the practices of drinking and holding a receptacle. They have already begun to be sensitive to connections between the concept milk and other concepts. As a result, when the word milk is uttered, it is a response not merely to the milk that it stands for but also to a range of other concepts. The representation in the utterance "milk" is preceded by a variety of inferential connections to other entities. The connection between the representation and what it represents is already rooted in a web of reasons. The conceptual capacities to engage with this web are distinctively human, and it is their distinctiveness that is not taken into account in the epistemological positions that McDowell interrogates. It is important not to underestimate this move within philosophy for it emerges from a tradition in thought from Kant through to Hegel that is still being furrowed and continues to offer fresh insights.

McDowell credits Brandom's writings and conversations with shaping his own thinking and singles out a seminar on Hegel's Phenomenology of Spirit that he attended in 1990:

the effect is pervasive; so much so that one way that I would like to conceive [Mind and World] is as a prolegomenon to a reading of the Phenomenology, much as Brandom's forthcoming Making It Explicit: Reasoning, Representing, and Discursive Commitment is, among many other things, a prolegomenon to his reading of that difficult text (McDowell, 1996, p. ix).

This startling statement invites us to take the distinctive character of both of their projects together. But while McDowell resists the so-called constructive philosophy, in favour of philosophy as therapy, he leaves us with a powerful restatement of how we might think of the development of mind (initiation into language and second nature). This does not lead to any pedagogic recommendations, but Brandom is different. He is willing to countenance constructive philosophy (providing new insights into the world and not to be confused with constructivism) and, as a result his work lends itself to a consideration of what is involved in the initiation into culture and tradition brought to our attention by McDowell. In addition, the legitimacy of making such a link here is the Hegelian turn in both their work. Both are concerned with an aspect of rational freedom-our responsiveness to reasons that makes us distinctively human. McDowell's concern with the extent to which modern naturalism has a grip on our thinking seeks a re-enchanted nature while Brandom's social pragmatism aims at putting human agency and with it recognition, at the heart of our thinking. Recognition is a technical term which features prominently in Hegelian philosophy for the way we take each other to be free and independent persons and as such, it is inextricably connected to how we are as conscious beings. The extent of our sociality is more than 
interaction and connection with each other, since our mindedness is constituted by this interaction. What matters for our purposes here is that McDowell and Brandom reach the same conclusion, albeit in different ways, that concepts are in play at the very point of awareness and when this position is recognised in education, important issues arise.

\section{Education and the significance of privileging the inferential}

When we think about an educative process conducted in contemporary classrooms, we might characterise it in the following way: A teacher will attempt to convey meaning by attending to the relation between representations and what they represent. They will be aware that they are faced with a group of learners who are each making a different sense of the representations that they have before them and so they will attempt to provide additional clarification and explanation to expand what lies behind the initial thought of what it is that is represented. Typically, a teacher will be under pressure to "cover" a particular topic and though they may wish to engage with each individual learner, the priority of ensuring that they "get through" the content of the lesson will ensure an economy of interaction. However, in an educational context where the priority may well be on what any representation stands for the question of how this connection arises is a matter of extreme pedagogical importance. Yet when teachers attend to the complexity of the individual meaning-making of learners, the nature of the particular knowledge domain in which that meaning-making occurs, and the inferential roles that constitute concept meaning, is often not the focus of attention. The idea that human beings construct meaning out of raw data (the Given referred to earlier) still forms the background to much educational thought and insufficient attention is paid to the interrelation of knowledge and learning (Noorloos et al., 2017). As a result, the lesson that we learn from Brandom is absent, namely, that the inferential should be privileged over the representational when we are considering the process by which learners acquire both meaning and knowledge (Bakker \& Derry, 2011; Derry, 2013).

Before this interrelation can be examined, it is necessary to consider both the significance of Brandom's privileging of the inferential over the representational and the central point underlying inferentialism, namely, that a distinctive characteristic of humanity is a quality of being responsive to reasons; that is, that we are beings capable of exercising rational freedom in a way that no other life form is. With freedom comes responsibility; hence, while a cat cannot be blamed for torturing a mouse, a human may. It is this crediting of individuals with responsibility for the content of their thoughts (concepts) that becomes so significant in an educational context. But all too often, it plays too limited a role.

Research demonstrates that the most effective interventions for the improvement of attainment are those that involve systematic interrogation of pupil understanding, whether through peer tutoring, forms of feedback or metacognitive and selfregulation strategies (Higgins et al., 2013). Though not made explicit in research reports, each of these successful interventions involves the inferential articulation of concept use, namely, making meaning explicit. On the teacher's part, this involves taking seriously what learners say and unpacking their attempt to articulate what they understand. This may involve showing the learners what they have committed themselves too and what is entailed by their commitments and as a result attending closely to 
the learner's reasoning, in effect teaching the learner to think. This is something that does not occur when teacher questioning fails to probe what lies behind learner responses.

As the focus of attention here is pedagogy, the need to appreciate what distinguishes us from other life forms or inanimate objects is crucial, in contrast to the examples earlier of chimpanzees and pigeons that conflate the actions of other animals with what appear to be similar actions of humans. Brandom contrasts the differential responsiveness of a parrot and a thermostat to that of a human and asks; "What is the knower able to do that ... the thermostat cannot? After all they may respond differentially to just the same range of stimuli" (Brandom, 2000, p. 162), crucially the response that the human is reliably disposed to produce is an inferentially articulated response. The parrot is just making a noise and the thermostat, a clicking sound. Whereas the human is making a claim by taking up a stance in an inferentially articulated space: "The knower has the practical know-how to situate that response in a network of inferential relations - to tell what follows from something being . . . cold, what would be evidence for it, what would be incompatible with it, and so on" (Brandom, 2000, p. 162). What is this "practical know-how" referred to here? It is the sort of know-how that allows the human to exclude the concept green when applying the concept red, which is a judgement that the parrot does not make when it successfully responds to the red stimulus by squawking "Red".

When we are concerned with formal education and the development of judgement and with it appropriate responsiveness, the adoption of a stance in an inferentially articulated space becomes crucial. For example, a young child may be responsive to certain features of a representation but not to others; for example, it may recognise as triangle shapes with angles of $45^{\circ}, 45^{\circ}$, and $90^{\circ}$ but exclude those shapes with angles of $30^{\circ}, 60^{\circ}$, and $90^{\circ}$. Jaworski (1994) used precisely this example when she considered how teachers should approach pupil responses. She related the anecdote of a teacher listening to two boys who were looking at a diagram of both triangles, one an isosceles right triangle and the other the $30^{\circ}, 60^{\circ}$, and $90^{\circ}$ triangle. One boy announced: "This one's a triangle [the first], and this one isn't [the second]". Jaworski used the example to question whether we should speak of the boy's concept of a triangle as a "mis"conception: "We might say that the boy was wrong and [the teacher] was right. But this is to make judgements about truth without taking into account the circumstances which the statement fits" (Jaworski, 1994, p. 20).

In raising this question, Jaworski echoes a theme in mathematics education literature concerned with avoiding the labelling of a pupil's response as a misconception that implies error, preferring instead to use a term such as "alternative conception" (Fujii, 2014). This is a tricky issue as Jaworski quite rightly wants to take account of the context or circumstances in which a statement is made when assessing its validity. However, the term "context" is insufficiently fine-grained to prevent the sort of problematic conflation that can arise in relation to knowledge. Jaworski, following Von Glaserfeld, asks “if there are 'mis'conceptions what then is a 'conception'? Is this some form of knowledge which the 'mis'conception is not? Is a conception independent of the person or circumstance of the conceiving?" (Jaworski, 1994, p. 20). The potential agnosticism in relation to epistemology suggests a conflation of different issues. To fully get to grips with what is happening in this example, we need an understanding not only of the boys' (what Brandom calls) commitments, that is, what 
the boy is doing when he makes a claim, but also of how the teacher engages with these commitments, that is, what the boy is in fact undertaking in making the claim. The boy is responsive to some inferences but not to all the ones that are necessary to hold the correct concept of a triangle in Euclidian geometry at the level appropriate for school knowledge. On the one hand, learners' commitments need to be examined when they restrict the concept of triangle to one figure rather than apply it to both. But on the other, the teacher needs to be aware that they are initiating the learner into a particular knowledge domain, one where the rules (norms) that define how the concept "triangle" may be used has arisen through the ongoing collective agreement of mathematicians developing and applying the concept in well-described domains throughout human written history. This ongoing collective commitment has not emerged in a vacuum but as the result of the constant testing of ideas within the material context in which they lie, throughout history.

Brandom puts it as follows:

The representational dimension of conceptual contents - the sort of correctness of concept application that answers to how things are with the things represented and that contrasts in principle with the sort of correctness that answers only to how things are taken to be by some individual or whole community - can be understood in terms of the inferential articulation that defines these contents. (Brandom, 1994, p. 607)

It is our capacity to be responsive to reasons and not simply caused to respond that allows our actions to be constrained by norms that we have collectively put in place, rather than by unmediated nature. Brandom, clarifies the basis of this freedom when he states that "The laws of nature do not bind us by obligation, but only by compulsion. The institution of authority is human work; we bind ourselves with norms" (p. 51). The idea that we institute norms that we then consent to bind ourselves by is central to the notion of freedom developed by Kant and German Idealism. Rather than the absence of constraint, freedom is defined by being bound by those norms that we ourselves endorse.

\section{Deontic scorekeeping—-keeping track of commitments and entitlements}

Norms develop and change over time, and associated with this development and change is the growth of knowledge and the lifting of our being beyond the limitations of any natural ecosystem. The development of norms depends, among other things upon, what Brandom metaphorically terms deontic scorekeeping, that is, the constant calibration of meaning through communication and dialogue. In this connection, it is important to appreciate just how radical the change in thinking about meaning is that Brandom has initiated.

Meaning is commonly thought of as arising directly through reference, namely, the meaning of the word "chair" is demonstrated by referring to the object that the word represents. Ultimately, meaning does involve representation but how this arises in the first place is crucial to our understanding of it, for it is here that rational freedom comes into play. If we examine how the meanings of words in sentences arise, we will find 
that these depend upon their connection to other words, and it is only through this process of connection that references can function in the first place. Words in a sentence can be likened to models. When we use models, we recognise that we are involved in a process of adjusting a systematic form in order that it may pick out features of the way the world works. Similarly, when we use concepts (words in sentences), we are committed to particular connections of these to other concepts; we are endorsing those connections by applying concepts in the particular way that we do. We have committed ourselves to certain connections that in turn entitle us to others and what we entitle ourselves to by the use of a particular concept may or may not coincide with the commitments of others. In the process of clarifying our commitments, we discover what we are actually entitled too rather than what we, at first glance, assume. Of course, when we apply or acquire concepts, we are not automatically thinking about this process as integral to our application. We may only focus on what we are committing ourselves to when an interlocutor challenges our application of a concept. The challenge may take the form of a direct questioning of our particular usage of a concept but it is normally part of a conversation whereby we each make fine adjustments to how we use a concept over the course of the dialogue to communicate in the first place. This, incidentally, is central to the experience of teaching as our understanding of a knowledge domain is actualised or even grasped fully for the first time by the very act of attempting to communicate. Norms do not simply arise out of an agreement of perspectives. Rather, it is the ongoing articulation of not only what each party is committed to but also to what they are in fact actually entitled to, regardless of what they take themselves to be entitled to, that funds objectivity. It is this ongoing process of keeping track of each other's commitments and entitlements that Brandom terms deontic scorekeeping.

Examining the details of a dialogue might normally involve working out what each party is arguing for, clarifying their points of agreement and disagreement, and identifying what positions they adopt and which they dissent from. Deontic scorekeeping captures the process of attributing meaning at a deeper level. In doing so, it not only attends to what is actually said and intended but to what actually is entailed or assumed, and it is the fleshing out of this detail that captures our answerability to how things are. Given that Brandom's work, laying out the detail of inferentialism, spans over 700 pages and leaving aside the difficulties established philosophers have had in getting to grips with his account, only the bare bones of what is meant by deontic scorekeeping can be provided here. The use of language entails endorsing particular ways of understanding the world. Often our endorsements may be sufficient for everyday life but not for more technical knowledge domains where precise and accurate relations between concepts are called for. For instance, when spiders are called insects, they are included in a group to which science no longer believes they belong. Despite this, the classification of spiders as insects may serve everyday purposes of responding to them in particular ways. For an entomologist whose concern is pest control, the class to which spiders belong, namely, arachnids (rather than insects), would have a significance that it does not for people in their everyday practice.

Actions are constrained by the world (including the practices) in which individuals find themselves and the continuation of the same actions endorse that way of taking the world to be. However, while the actions of other sentient creature's actions are also 
constrained by their environments, these creatures are not in the business of distinguishing correct and incorrect ways of taking the world. A toddler entering a library will not know that quiet is required and thus fail to distinguish the library from a play area. How the toddler takes the library, namely, as an environment where noise may be made, is incorrect; it does not follow the rules (norms) that define behaviour in the library or are consistent with the concept of library as a particular social institution. As the child's knowledge grows, it will learn to take the library in an appropriate way, operating with the correct endorsement unless, as school children often do, they rebel against library rules, that is, purposely take the library in a different way. Even then, their rebellion is only meaningful as rebellion in the context of the rules that define the library. Freedom to endorse in one way or another is the mark of human reason. In effect as a child develops their understanding of a concept, whether of a social institution or of a mathematical concept, they situate their new response in a network of inferential relations involving what is entailed by and what follows from the particular endorsements they apply.

Endorsing particular inferential relations resulting in definite commitments is evidently not an isolated achievement. What I am able to attribute to an event or an object of my attention is not exclusively dependent merely on my own undertakings, nor is it simply responsive to the undertakings of others. Our responses arise within the constraints of the existing social and material world we inhabit. It is the triangulation of shared responses in conjunction with the environment we inhabit which maintains the norms that distinguish one response from another. Brandom uses the example of chess to convey this sense of appropriate responses being constrained by the specificities of the context in which they arise. What I commit myself to, what norms I wish to hold by are not dependent on my subjectivity alone. It may be up to me whom I recognise as excellent chess players to measure my own standard of chess playing; but it is not up to me alone to define myself an excellent chess player. To achieve that status, I need to be recognised as such by others: "To be, say a formidable club player, I must be recognised as such by those I recognise as such" (Brandom, 2009, p. 71). When I take matters to be a certain way, when I use concepts, that usage is not onesidedly dependent on me alone. While I am bound by norms that I choose individually, these norms are always instituted collectively.

Brandom's use of the image of a game of giving and asking for reasons captures the ongoing scorekeeping of what a concept means, that is, what its inferential role is. As our commitments change so its role changes. Brandom continues his scorekeeping analogy by talking of the deontic score, namely, the score that marks changes in my endorsements and in what commitments I undertake as what I attribute alters. His central point is that to understand ourselves as knowers, we need to reverse the conventional order of explanation which privileges representation over inference. For Brandom, Hegel completed the inversion of the traditional order of semantic explanation begun by Kant, "by beginning with a concept of experience as inferential activity and discussing the making of judgments and the development of concepts entirely in terms of the roles they play in that inferential activity" (p. 92). This approach is at odds with thought conceived in terms of individual mental states and words understood as the names for things, events or states of affairs. The emphasis placed by Brandom, following Hegel, on the significance of social relations in the generation of knowledge directs attention not only to the development of reasoning processes but also, given 
normativity (the process by which we are responsive to reasons), to the systematic character of knowledge.

\section{The social articulation of concepts}

The application of any concept illustrates the systematic character of knowledge. For instance, the precise meaning of any concept will depend upon its location within a particular domain of knowledge. Whether the word is a technical term such as "gene" or an everyday term such as "friend", the precision of its meaning will depend upon the context of use. In the former case, one would expect a concept's use to be precise; however, even in the case of a scientific term, the meaning of a concept will vary according to the history of its development and use. So for instance,

Moss (2003) argues that the term 'gene' figures in two distinct explanatory games in molecular biology. Each of these two sets of inference motivated by the gene concept is legitimate in its appropriate context, but conflation then leads to fallacious inferences and an inappropriate version of genetic determinism (Brigandt, 2010, p. 8).

The idea that a concept's meaning is constituted by its relation to other concepts was central to Vygotsky's account of the development of intellect and of the capacity to think abstractly. According to Vygotsky, "the capacity for deduction is only possible within a definite system of relationships among concepts" (Vygotsky, 1987, p. 192). Within such a system, sensitivity to inconsistency arises. An interesting illustration can be seen in Donaldson's and her colleagues' redesign of Piaget's and Inhelder's test of young children's ability to take a perspective other than their own in the "three mountain task" (Inhelder \& Piaget, 1967). The redesign of the task demonstrates the importance of systematicity for meaning. In the "Three mountains task" experiment, where children were asked to decide what picture of a mountain scene represented the view of a doll placed in a position other than their own, they failed to distinguish the view of the doll from their own. This supported Piaget's argument that young children are egocentric and unable to take a perspective other than their own. In the redesigned task, Donaldson and her co-experimenters replaced the mountain scene with one where the child was asked to hide a "naughty" doll from a policeman doll (i.e. to hide the doll successfully, the child had to take the perspective of the policeman doll). Children taking the "policeman task" proved themselves able to adopt a perspective different from their own thereby demonstrating that the language and design used by experimenters play crucial parts. Donaldson explained the success of the children in terms of the fact that the task "requires the child to act in ways which are in line with certain very basic purposes and intentions (escape and pursuit)..." (Donaldson, 1978, p. 24). However, what is also interesting in the task design is the extent to which children have access to the norms that constitute the task. In the redesigned experiment, the reasons or norms are visible as everything is explicitly dependent upon everything else in a way that was not the case in the original mountain task. In Brandom's terms, we may say that the inferential structure of the task is available to the child. 
Vygotsky is well known for the criticism he made of Piaget's early work for its failure to attend to conscious awareness and the distinctive conditions in which this is actualised for the young child (2013). Vygotsky explains;

Only within a system can the concept acquire conscious awareness and a voluntary nature. Conscious awareness and the presence of a system are synonyms when we are speaking of concepts, just as spontaneity, lack of conscious awareness, and the absence of system are three different words for designating the nature of the child's concept (Vygotsky, 1987, p. 191).

It could be argued that perspective taking is realised for the child in the redesigned task precisely because the elements in the task are connected to each other systematically, that is, the task makes visible the "reasons that follow from" and the "reasons that are implied by" the task's events.

For Vygotsky, systematicity relates to what is distinctive about human engagement with the world. This engagement comprises a transformation of the world achieving a form of control beyond the reach of any other animal. In transforming the world, humans attribute significance to everything they engage with and the accompanying reasons and concepts they employ that constitute meanings necessarily have a systematic character. Systematicity and modelling as a feature of our engagement in the world is explored by the philosopher Joseph Rouse. Rouse (2011) provides an account of the development of our knowledge of genes through the way in which certain experimental designs, involving the development of a microworld, opened up the "inferential articulation" of the concept in a new way. Leaving aside interesting issues in philosophy of science in the account provided by Rouse, what emerges, as a distinguishing feature of human beings, is that we mediate our existence and express new potentials through the creation of technologies (models, algorithms, pictures, scientific theories).

\section{Papert}

However, do students and teachers understand their engagement with knowledge in this way? Central to Papert's and his colleagues' development of LOGO, at MIT, was the creation of an environment in which learners could experiment with designs. Their aims appear to coincide with an inferentialist approach to learning. Papert's dream was to create a mathematics classroom that replicated the energy and purposiveness of the art classroom where student built soap sculptures:

what each student carved came from wherever fancy is bred and the project was not done and dropped but continued for many weeks. It allowed time to think, to dream, to gaze, to get a new idea and try it and drop it or persist, time to talk, to see other people's work and their reaction to yours-not unlike mathematics as it is for the mathematician (Papert \& Harel, 1991).

However, absent from this vision of learning was the extent to which LOGO was clearly bounded by the parameters of geometry and consequently had an internal 
systematicity. The student acquires a concept of a triangle by engaging in the microworld of LOGO which necessarily entails definite rules for success or, to put it in the language of inferentialism, ensures that the student acknowledged the rules (norms) that define the triangle.

The explicitness of a software programme or of a formal argument expressed in a series of propositions might suggest that engagement in an inferential domain such as LOGO is purely linguistic, whether it is that of mathematics or of English. However, what is absent in this account is the sense that we become attuned to environments in ways that ensure we are responsive to the appropriate reasons despite formal knowledge of what these reasons are. The adept and skilful surgeon, the farm child who knows about horses having grown up with them - each respond to reasons in an appropriate way but these are not due solely to the formal reasons laid out explicitly in warranted sentences. These are the sedimented reasons laid down in human practices. Responsiveness to reasons need not be understood as necessarily explicit. Reasons may serve in the background to intelligent action but even in the background they exert normative constraints distinguishing correct rather than incorrect actions.

\section{Teacher judgement}

In formal education, the teacher initiates children into a distinctive domain of knowledge, into what it is to do mathematics, history, biology and so on, while children become responsive to the reasons that constitute the particular use of concepts which form the disciplines into which they are being initiated.

Teachers who adopt an inferentialist approach are sensitive to the inferential connections that constitute concepts, namely, the norms that regulate the use of any concept in a particular knowledge domain. This will inform how they approach a topic, the extent of dialogue and modelling involved, and the expectations of what learners can achieve. Their success as teachers will also draw upon practical wisdom or what Aristotle called phronesis. This capacity to make appropriate responses in situations where clear cut rules may not be appropriate is not acquired by the type of template, much loved by policy makers aiming at what Dunne (2011) pejoratively called "practitioner-proof" practice. Rather, they require qualities of listening, of respect for the individuals who make up a classroom and an interest in engaging with their reasoning, taking utterances seriously and unpacking the commitments entailed in such utterances. What remains after the formalised props are taken away is the importance of an inferentialist orientation to knowledge: humility about the extent of the knowledge domain and an openness to the giving and asking for reasons. The teacher who presupposes minds composed of mental states that assimilate representations with great or lesser degree of ability and who thinks of knowledge as "revealed... [as] part of God's handiwork, waiting to be discovered" (Hacking, 1983, p. 225), will surely fail to engage and inspire young learners.

The appliance of inferentialism to education does not entail the creation of a codified system of "what is a reason for what". The absence of an explicit framework may be a source of anxiety for educators compelled to rely on pedagogic prescriptions. However, when the critical role of the good judgement is not recognised, educational projects are surely doomed to fail. 
In the face of this, a major contribution of inferentialism is to provide insight into the conditions in which good judgement emerges. In addition, by revealing the significance of normative constraints, responsiveness to reason and of social articulation to thinking and knowledge, it opens new possibilities for critically examining the appropriateness of pedagogical approaches and the presuppositions that inform them.

The application of inferentialism to education, to the humanities and to the social sciences is a recent development; as a result, the articulation of the ideas, their strengths and weaknesses in particular cases, has only just begun. The papers that follow attend to the consequences of giving prominence to the inferential rather than the representational in mathematics education and in so doing, they begin the process of articulating inferentialism in the area most central to the human condition-learning.

Open Access This article is distributed under the terms of the Creative Commons Attribution 4.0 International License (http://creativecommons.org/licenses/by/4.0/), which permits unrestricted use, distribution, and reproduction in any medium, provided you give appropriate credit to the original author(s) and the source, provide a link to the Creative Commons license, and indicate if changes were made.

\section{References}

Bakhurst, D. (2011). The formation of reason. Oxford: Wiley-Blackwell.

Bakker, A., \& Derry, J. (2011). Lessons from inferentialism for statistics education. Mathematical Thinking and Learning, 13(1-2), 5-26.

BBC News Item (2007) Chimps Are Smarter Than Us. Retrieved, 15.09.2016, from YouTube. https://youtu. be/GMHiOCD-0aI

Brandom, R. (1994). Making it explicit: reasoning, representing, and discursive commitment. Cambridge, MA: Harvard University Press.

Brandom, R. (2000). Articulating reasons: an introduction to inferentialism. Cambridge, MA: Harvard University Press.

Brandom, R. (2009). Reason in philosophy: animating ideas. Cambridge, MA: Belknap Press.

Bransen, J. (2002). Normativity as the key to objectivity: an exploration of Robert Brandom's articulating reasons. Inquiry, 45(3), 373-392. doi:10.1080/002017402760258204.

Brigandt, I. (2010). Scientific reasoning is material inference: combining confirmation, discovery, and explanation. International Studies in the Philosophy of Science, 24(1), 31-43. doi:10.1080 /02698590903467101.

Canale, D., \& Tuzet, G. (2007). On legal inferentialism: toward a pragmatics of semantic content in legal interpretation? Ratio Juris, 20(1), 32-44.

Cobb, P. (2007). Putting philosophy to work: coping with multiple theoretical perspectives. In F. K. Lester Jr. (Ed.), Second handbook of research on mathematics, teaching and learning (pp. 3-30). Charlotte, NC: National Council of Teachers of Mathematics.

Derry, J. (2013). Vygotsky: philosophy and education. Oxford: Wiley-Blackwell.

Donaldson, M. (1978). Children's minds. New York: W. W. Norton.

Dunne, J. (2011). Professional wisdom' in 'practice'. In L. Bondi, D. Carr, C. Clark, \& C. Clegg (Eds.), Towards professional wisdom (pp. 13-26). Farnham: Ashgate.

Erman, E. (2010). Freedom as non-domination or how to throw the agent out of the space of reasons. Journal of Power, 3(1), 33-51.

Fujii, T. (2014). Misconceptions and alternative conceptions in mathematics education. In S. Lerman (Ed.), Encyclopedia of mathematics education. New York: Springer.

Hacking, I. (1983). Representing and intervening: introductory topics in the philosophy of natural science. Cambridge: Cambridge University Press.

Herbranson, W. T., \& Schroeder, J. (2010). Are birds smarter than mathematicians: pigeons (Columba livia) perform optimally on a version of the Monty hall dilemma. Journal of Comparative Psychology, 124(1), $1-13$. 
Higgins, S., Katsipataki, M., Kokotsaki, D., Coleman, R., Major, L.E., \& Coe, R. (2013). The Sutton trusteducation endowment foundation teaching and learning toolkit. London: education endowment foundation. Available at http://www.educationendowmentfoundation.org.uk/toolkit

Inhelder, B., \& Piaget, J. (1967). The child's conception of space. New York: W. W. Norton.

Jaworski, B. (1994). Investigating mathematics teaching: a constructivist enquiry. London: Falmer.

Klatt, M. (2008). Making the law explicit: the normativity of legal argumentation. Oxford: Hart Publishing.

Macbeth, D. (2009). An antinomy of empirical judgment: Brandom and McDowell (translated from the original Italian). In L. Ruggiu \& I. Testa (Eds.), Lo Spazio Sociale della Ragione: De Hegel in Avanti (Part 4: Chapter 4). Milan: Mimesis.

Marshall, D. L. (2013). The implications of Robert Brandom's inferentialism for intellectual history. History and Theory, 52(1), 1-31. doi:10.1111/hith.10651.

McDowell, J. (1996). Mind and world. Cambridge, MA: Harvard University Press.

Miller, G. A. (2003). The cognitive revolution: a historical perspective. Trends in Cognitive Sciences, 7(3), 141-144. doi:10.1016/S1364-6613(03)00029-9.

Moss, L. (2003). What Genes Can't Do. Cambridge MA: MIT Press.

Noorloos, R., Taylor, S., Bakker, A., \& Derry, J. (2017). Inferentialism as an alternative to socioconstructivism in mathematics education. Mathematics Education Research Journal.

Papert, S., \& Harel, I. (1991). Constructionism, Ablex Publishing Corporation. Accessed on 15.09.2016, http://namodemello.com.br/pdf/tendencias/situatingconstrutivism.pdf

Papert, S. (1993). The Children's machine: rethinking School in the Age of the computer. New York: Basic Books.

Peregrin, J. (2014). Inferentialism: why rules matter. Basingstoke GB: Palgrave Macmillan.

Rouse, J. (2011). Articulating the world: experimental systems and conceptual understanding. International Studies in the Philosophy of Science, 25(3), 243-254. doi:10.1080/02698595.2011.605246.

Sellars, W. (1997). Empiricism and the philosophy of mind: with an introduction by Richard Rorty and a study guide by Robert Brandom. Cambridge, MA: Harvard University Press.

Stekeler-Weithofer, P. (Ed.). (2008). The pragmatics of making it explicit. Amsterdam, NL: John Benjamins.

Testa, I. (2009). Second nature and recognition. Hegel and the social space. Critical Horizons, 10(3), 341-370.

Vygotsky, L. S. (1987). The collected works of L.S. Vygotsky: volume 1 - problems of general psychology; including the volume thinking and speech. In R. W. Reiber \& A. S. Carton (Eds.). New York: Plenum Press.

Wigner, E. P. (1960). The unreasonable effectiveness of mathematics in the natural sciences. Richard Courant lecture in mathematical sciences delivered at New York University, may 11, 1959. Communications in Pure and Applied Mathematics, 13(1), 1-14. doi:10.1002/cpa.3160130102.

Williams, J. \& Brandom, R. (2013). Inferential man: an interview with Robert Brandom. Symplokē, 21(1-2), 367-391. 